\title{
Is temperature-index derivative suitable for China?
}

\section{Article}

\section{Accepted Version}

Creative Commons: Attribution-Noncommercial-No Derivative Works 4.0

Cui, H., Zhou, Y., Dzandu, M. D., Tang, Y. and Lu, X. (2019) Is temperature-index derivative suitable for China? Physica A:

Statistical Mechanics and its Applications, 536. 120959. ISSN 0378-4371 doi: https://doi.org/10.1016/j.physa.2019.04.195 Available at https://centaur.reading.ac.uk/88838/

It is advisable to refer to the publisher's version if you intend to cite from the work. See Guidance on citing.

To link to this article DOI: http://dx.doi.org/10.1016/j.physa.2019.04.195

Publisher: Elsevier

All outputs in CentAUR are protected by Intellectual Property Rights law, including copyright law. Copyright and IPR is retained by the creators or other copyright holders. Terms and conditions for use of this material are defined in the End User Agreement.

\section{www.reading.ac.uk/centaur}

\section{CentAUR}

Central Archive at the University of Reading

Reading's research outputs online 


\title{
Is temperature-index derivative suitable for China?
}

\author{
Hairong Cui ${ }^{a, *}$, Ying Zhou ${ }^{a}$, Michael D. Dzandu ${ }^{b}$, Yinshan Tang ${ }^{b}$, Xunfa Lu ${ }^{a}$ \\ a School of Management Science and Engineering, Nanjing University of Information Science and \\ Technology, Nanjing 210044, China \\ b Informatics Research Center, Henley Business School, University of Reading, Reading RG6 6UD, UK
}

\section{H I G H L I G H T S}

- We explored whether temperature derivatives traded on CME are suitable to China.

- Cluster analysis in form of model parameters from the AR-EGARCH model is used to classify temperature data.

- Asymmetry of the volatility of the temperature is confirmed according to the AR-EGARCH model.

- HDD and CAT in Europe and CAT* in Japan can be used directly in Nanjing of China.

\section{A R T I C L E I N F O}

\section{Article history:}

Received 27 January 2018

Received in revised form 4 October 2018

Available online $\mathrm{xxxx}$

\section{Keywords:}

Weather risk

Temperature derivatives

Cluster analysis

Shock asymmetry

AR-EGARCH model

\begin{abstract}
A B S T R A C T
In this paper, we assessed the suitability of temperature derivatives for China through modeling. We assumed that if the physical dynamics of temperature of some cities are identical, then the same types of temperature derivatives can be used in these cities. Nearly twenty years temperature data of forty-seven cities with traded temperature derivatives on the Chicago Mercantile Exchange Group (CME) and seven Chinese cities were collected and analyzed in a two-step approach. Firstly, the AR-EGARCH model capturing the shock asymmetry of the volatility of temperature is used to simulate the dynamics of temperature of the cities. Secondly, the temperature of the cities are classified through cluster analysis based on model parameters from the AR-EGARCH model. The results showed that the fitting effect of the AR-EGARCH model is very good, and only a few cities did not display the shock asymmetry. The model for Nanjing fitted well into one of the categories of the cities in the CME; but the other six Chinese cities belong to new categories, which are different from the cities in the CME. We concluded that HDD and CAT in Europe and CAT* in Japan can be used directly in Nanjing, but the existing temperature derivatives in CME were unsuitable for the other six Chinese cities. Recommendations for the establishment of weather derivatives market in China have been proposed.
\end{abstract}

(C) 2019 Elsevier B.V. All rights reserved.

\section{Introduction}

In recent decades, extreme weather has occurred frequently across the world, which seriously impedes the development of world economies. Countries are therefore actively taking measures to deal with climate changes for sustainability. One of the financial instruments used to hedge weather risk is weather derivative [1-3]. In 1997, the United States launched the first weather derivative. In 1999, weather derivatives were traded formally on the Chicago Mercantile

\footnotetext{
* Correspondence to: No.219, Ningliu Road, Nanjing, 210044, China.
}

E-mail address: cuihairong@nuist.edu.cn (H. Cui). 
Exchange Group (CME). Later, many countries such as Britain, France, Germany, Japan and many others also joined in. However, until date, China has no weather derivatives. Although there are some weather insurance products and related instruments of weather risk management in China, the weather derivatives market remains unexploited.

In general, weather risk is divided into catastrophic weather events and non-catastrophic weather events [4]. For catastrophic weather events, which cover rare weather events such as extreme cold or heat, hurricanes and floods, the solutions in China are usually availability of government bailout, social contributions and weather insurance products. In contrast, weather derivatives are designed to cover non-catastrophic weather events. Rainy or dry and warm or cold periods, which are expected to occur frequently, can reduce the economic revenue of a sector by affecting the volume of sales. Weather derivatives are mainly used to avoid the volume risk of weather. The weather changes in China are quite different in different regions so that non-catastrophic weather events frequently occur. However, there are no management tools for volume risk of weather events for the various economic sectors. Therefore, it is necessary for China to introduce weather derivatives. However, the introduction of weather derivatives into China requires an assessment of its suitability. Studies on weather derivatives related to climate conditions in China have not been fully developed $[5,6]$, especially on the types of weather derivatives suitable for China.

While the direct adoption of mature weather derivatives in CME may be the most convenient way for China, an initial assessment of its suitability for China through Modelling techniques would provide practical indications of its feasibility. Most weather derivatives contracts are traded in the CME. According to CME, there are many types of weather derivatives including but not limited to temperature derivatives, hurricane derivatives, frost derivatives, and snowfall derivatives among others. Weather derivatives have a strong regional feature and its applicability could be context specific [7,8]. For example, weather derivatives in a city may not be suitable for other cities. Therefore, the purpose of this paper is to study whether the existing temperature derivatives on the CME can be used in China.

This paper is based on one key assumption. For the convenience of the research, we assumed that when temperatures in two cities have the same dynamic evolution, the two cities can use the same types of temperature derivatives. Cluster analysis was used to classify the temperature data of all the cities, which have weather derivatives on the CME, and seven cities in China. Consequently, we identified and grouped similar class members of the temperature data; and determined whether the seven Chinese cities should introduce temperature derivatives and if so, the types of temperature derivatives. Given that ordinary cluster analysis is only suitable for static data, and temperature data is a time series dynamic data, which has high dimensional feature, we used cluster analysis based on the AR-EGARCH model to classify the temperature data. At first, we used the AR-EGARCH model to fit the temperature data, and then classify the temperature data based on the model parameters through cluster analysis. The AR-EGARCH model used to model the dynamics of temperature is an improvement of the AR-GARCH model proposed by Campbell and Diebold [9]. Compared with the GARCH model, EGARCH model can capture the asymmetry of the volatility of time series. Studies show that many financial time series have the asymmetry of the volatility $[10,11]$. That is, the impact of good news and bad news on the volatility is not the same. The temperature fluctuation also has the asymmetry [12,13], consequently extreme cold and heat have different impact on the volatility of temperature.

The organization of this paper is as follows. In Section 2, we reviewed the related literature on weather derivatives; in Section 3, we introduce the data and methodology used in this paper. Section 4 is the data analysis and results, and Section 5 outlines our conclusions and recommendations.

\section{Literature review}

Pricing of weather derivatives is a task. In contrast to other assets, the underlying asset of weather derivatives is not tradable, and the corresponding market is relatively illiquid. So, the traditional non-arbitrage pricing theory (such as Black-Scholes pricing model) cannot be applied directly [14,15]. Almost all weather derivatives are based on temperature indices [16]. As a result, many pricing methods of temperature derivatives have been proposed in literature.

The actuarial method and the historical burn analysis (HBA) proposed earlier derive the price of derivatives by calculating the average (discounted) payoff of the historical performance of a temperature derivative. The actuarial method and the historical burn analysis are not based on the dynamics of the temperature itself [17]. Another method called "Index Modelling" [18,19], can model directly the temperature index, such as HDD, CDD, and CAT, to derive the pricing of derivatives. However, the shortcoming of Index Modelling is that different indices need different models. Therefore, Daily Modelling is proposed, which can model directly the daily temperature for pricing derivatives, no matter what kind of index [20]. Ahčan [21] held that under the assumption that market price of risk is zero; Daily Modelling can get the no-arbitrage pricing model of derivatives.

There are two methods proposed for modeling daily temperature: one assumes a continuous process of the temperature; another, a discrete process [22]. The continuous process uses a diffusion stochastic differential equation, such as a mean-reverting form, as used by Alaton et al. [23], Benth [24], Benth and Saltyte-Benth [25,26], Benth et al. [27,28], Zapranis and Alexandridis [29-31]. However, when one estimates the model parameters, the temperature has to be discretized. Moreno [32] thought a discrete process should be more reasonable, because temperature does not change continuously, as we know.

For a discrete process, many researchers make use of a general autoregressive moving average framework (e.g. GARCH). For example, Tol [33] used the GARCH model to capture the systematic variation of the volatility of temperature from the 
Table 1

Cities which introduced temperature derivatives in CME.

\begin{tabular}{|c|c|c|c|c|c|c|}
\hline Country/Region & United States & & Europe & Canada & Australia & Japan \\
\hline City & $\begin{array}{l}24 \text { Cities- } \\
\text { Atlanta } \\
\text { Baltimore } \\
\text { Boston } \\
\text { Chicago } \\
\text { Cincinnati } \\
\text { Colorado Springs } \\
\text { Dallas } \\
\text { Des Moines } \\
\text { Detroit } \\
\text { Houston } \\
\text { Jacksonville } \\
\text { Kansas City }\end{array}$ & $\begin{array}{l}\text { Las Vegas } \\
\text { Little Rock } \\
\text { Los Angeles } \\
\text { Minneapolis } \\
\text { New York } \\
\text { Philadelphia } \\
\text { Portland } \\
\text { Raleigh } \\
\text { Sacramento } \\
\text { Salt Lake City } \\
\text { Tucson } \\
\text { Washington D.C. }\end{array}$ & $\begin{array}{l}11 \text { Cities- } \\
\text { Amsterdam } \\
\text { Barcelona } \\
\text { Berlin } \\
\text { Essen } \\
\text { London } \\
\text { Madrid } \\
\text { Oslo } \\
\text { Paris } \\
\text { Prague } \\
\text { Rome } \\
\text { Stockholm }\end{array}$ & $\begin{array}{l}6 \text { Cities- } \\
\text { Calgary } \\
\text { Edmonton } \\
\text { Montreal } \\
\text { Toronto } \\
\text { Vancouver } \\
\text { Winnipeg }\end{array}$ & $\begin{array}{l}3 \text { Cities- } \\
\text { Brisbane } \\
\text { Melbourne } \\
\text { Sydney }\end{array}$ & $\begin{array}{l}3 \text { Cites- } \\
\text { Hiroshima } \\
\text { Osaka } \\
\text { Tokyo }\end{array}$ \\
\hline
\end{tabular}

Table 2

Temperature derivatives in CME.

\begin{tabular}{llll}
\hline City locations & Index used-winter & Index used-summer & Time frames for contracts \\
\hline United States & HDD & CDD & Weekly,Monthly,Seasonal Srip:October through April for \\
& & & Winter, April through October for Summer \\
Europe & HDD & CAT & Monthly, Seasonal Strip:Same as U.S. contracts \\
Canada & HDD & CAT,CDD & Monthly, Seasonal Strip:Same as U.S. contracts \\
Australia & HDD & CDD & Monthly, Seasonal Strip:Same as U.S. contracts \\
Japan & CAT $^{*}$ & CAT* & Monthly, Seasonal Srip:October through April for \\
& & Winter, April through October for Summer
\end{tabular}

Note: this form is from www.cmegroup.com/weather.

Netherlands. Franses et al. [12] proposed a non-linear GARCH model for the weekly temperature from the Netherlands. Taylor and Buizza [34,35] expanded the works of Tol [33] and Franses et al. [12] and used a low-order Fourier series to model the seasonality of temperature.

Cao and Wei [36] also built their unique framework, which is different from the stochastic differential equation. However, their model probably cannot forecast for long time periods. Campbell and Diebold [9] expanded the model of Cao and Wei [36]. They use a low-order Fourier series with autoregressive lags to model the seasonal mean and the conditional variance. However, the model needs large datasets for parameters estimation to reveal a long memory in dynamics of the temperature because the maximum number of lags in the model could be as high as 25. Bellini [37] think large datasets probably deteriorate the quality of the time trend. Similarly, Caporin \& Preś [38] used an ARFIMA-GARCH model to measure the long memory of the temperature. They observed that fitting ARFIMA model needs a lot of time.

Svec and Stevenson [39] compared various models in modeling and forecasting Daily Average Temperature. These models are the modification of the AR-GARCH model proposed by Campbell and Diebold [9]. The results show that the modified models are better than the original model. In this paper, we also expanded the study of Campbell and Diebold [9]. However, differently with the above-modified models, we have incorporated a parameter, which captures the asymmetry of the volatility of the temperature into the original model.

\section{Data and methodology}

\subsection{Data}

Data for the study was collected from all temperature derivatives and temperature data of the corresponding fortyseven cities in CME. According to CME and [8], we tidy up the cities, which introduced temperature derivatives in CME. Table 1 shows the forty-seven cities with traded temperature derivatives in CME and Table 2 shows the types of temperature derivatives that every city used.

Temperature derivatives for winter (from October to April) and summer (from April to October) in the U.S. and Australia are all based on the Heating Degree Day (HDD) index and the Cooling Degree Day (CDD) index. In Europe, there are HDD and the Cumulative Average Temperatures (CAT); in Canada, there are HDD, CDD and CAT; and in Japan, there is CAT*. Both CAT and CAT* belong to the cumulative average temperature derivatives, but with different daily average temperature. There are two kinds of daily average temperatures defined by CME. The first is the arithmetic average of daily maximum temperature and minimum temperature $\left(\mathrm{DAT}_{1}\right)$. The second is the arithmetic average of hourly temperature accumulated over a 24-h period $\left(\mathrm{DAT}_{2}\right)$. CAT index uses the first definition, while CAT* uses the second.

Based on our main assumption, we purposively selected seven cities in China with different socio-economic and geographical characteristics. These are Harbin, Beijing, Jinan, Shanghai, Nanjing, Shenzhen and Sanya. To some extent, the development of these cities is more easily affected by temperature changes. The seven cities are all located in the 
East of China, but distributed from north to south so that the sample data between different cities are heterogeneous, which is good for classification. Every city has its own characteristics. Harbin is an important central city located in the Northeast part of China. Harbin is also a famous tourist city, and International Ice and Snow Cultural Festival is held there every year. Beijing is the capital of China. Jinan is the capital of Shandong province, China. Shandong province is a big agricultural province, whose GDP is the third in China. Temperature changes have an important influence on Agricultural. Shanghai is the center of economy and finance of China. Nanjing is the capital of Jiangsu province, China. Jiangsu province is one of the economically developed provinces in China. Shenzhen as an economic center is the window of opening up of China. Sanya is a coastal and tourist city.

A lot of effort went into getting data of each city for nearly twenty years except Vancouver. For Vancouver, just four years data are collected, but it is enough for estimating EGARCH model. Data interval and volume are shown in Table 3 and the 29th February of the leap year is removed from the sample. Although the data span of each city is different, it does not affect the classified results because our classification is based on the model parameters, rather than the data itself. This is the advantage of clustering in the form of model parameters, and it has enough robustness. For United States, Europe, Canada, and Australia, we collected DAT 1 , for Japan, DAT 2 ; and for the seven Chinese cities, DAT 1 and $\mathrm{DAT}_{2}$. It amounts to sixty-one sets of time series data. All the data for the study were sourced from the CME's Website: www.cmegroup.com/weather and the NOAA's Website: www.noaa.gov.

Fig. 1 shows the original $\mathrm{DAT}_{1}$ distribution $\left({ }^{\circ} \mathrm{F}\right)$ of selected cities from 1 January 2014 to 31 December 2015. The temperature distribution of these cities has obvious seasonal variation. The variation of temperature in summer (peak) is larger than that in winter (valley) in Bankstown, Melbourne and Amsterdam. That is, the volatility of temperature in summer is greater than that in winter. On the other hand, the variation of temperature in winter (valley) is larger than that in summer (peak) in Tucson, Shenzhen, and Sanya. That is, the volatility of temperature in winter is greater than that in summer. It seems to imply that the variability of temperature is asymmetric.

\subsection{The AR-EGARCH model}

Franses et al. [12] avers that four characteristics of the temperature must be taken into account when constructing the dynamic model of the temperature: (a) the seasonality of temperature itself; (b) the seasonality of the volatility; (c) the aggregation of the volatility; and (d) the asymmetry of the volatility. Campbell and Diebold [9] proposed the ARGARCH model, which can reflect the first three characteristics of temperature changes but cannot catch the asymmetry of the volatility. Therefore, we used the EGARCH model to replace GARCH model in AR-GARCH model. Cui et al. [40] used AR-EGARCH model to study the temperature from individual cities in China and their result shows that AR-EGARCH model can catch the asymmetry of the volatility of temperature, and the effectiveness of fitting and prediction with the AR-EGARCH model is better than that of the AR-GARCH model.

AR-EGARCH model is as follows:

$$
\begin{aligned}
& T_{t}=\text { Trend }_{t}+\text { Seasonal }_{t}+\sum_{l=1}^{L} \rho_{t-l} T_{t-l}+\sigma_{t} \varepsilon_{t} \\
& \ln \sigma_{t}^{2}=\alpha_{0}+\sum_{q=1}^{Q}\left(\lambda_{c, q} \cos \left(2 \pi q \frac{d(t)}{365}\right)+\lambda_{s, q} \sin \left(2 \pi q \frac{d(t)}{365}\right)\right)+\sum_{i=1}^{I}\left(\alpha_{i} \frac{\left|\varepsilon_{t-i}\right|}{\sigma_{t-i}}+\gamma_{i} \frac{\varepsilon_{t-i}}{\sigma_{t-i}}\right)+\sum_{j=1}^{J} \beta_{j} \ln \sigma_{t-j}^{2}
\end{aligned}
$$

where,

$$
\begin{aligned}
& \text { Trend }_{t}=\sum_{r=0}^{R} \phi_{r} t^{r}, \varepsilon_{t} \underset{\text { i.i.d }}{\sim} N(0,1) \\
& \text { Seasonal }_{t}=\sum_{p=1}^{P}\left(\delta_{c, p} \cos \left(2 \pi p \frac{d(t)}{365}\right)+\delta_{s, p} \sin \left(2 \pi p \frac{d(t)}{365}\right)\right)
\end{aligned}
$$

$T_{t}$ is a temperature variable. $\phi_{r}, \delta_{c, p}, \delta_{s, p}, \rho_{t-l}, \lambda_{c, q}, \lambda_{s, q}, \alpha_{i}, \beta_{j}$ and $\gamma_{i}$ are parameters. $d(t)(t=1, \ldots, 365)$ is a repeated periodic function, excluding 29th February in leap year.

Eq. (1) is the conditional mean equation. Trend $_{t}$ is a time trend, reflecting the impact of global warming on temperature. Seasonal $l_{t}$ is a Fourier series used to describe the seasonality of temperature itself. $\sum_{l=1}^{L} \rho_{t-l} T_{t-l}$ shows the auto-regressive characteristic of temperature. That is the temperature over the past few days will have an impact on the temperature today.

Eq. (2) is the conditional variance equation. There is still a Fourier series used to describe the seasonality of the volatility. $\gamma_{i}$ is a parameter of the asymmetric effect. If $\varepsilon_{t-i}>0$, the total effect of $\varepsilon_{t-i}$ is $\left(\alpha_{i}+\gamma_{i}\right)\left|\varepsilon_{t-i}\right|$. If $\varepsilon_{t-i}<0$, the total effect of $\varepsilon_{t-i}$ is $\left(\alpha_{i}-\gamma_{i}\right)\left|\varepsilon_{t-i}\right|$. Different symbol of $\gamma_{i}$ reflects the asymmetric effects of positive and negative information. For example, in a financial market, bad (negative) information usually brings greater impact on the volatility, so $\gamma_{i}$ is negative. 
Table 3

Data interval and volume of cities.

\begin{tabular}{|c|c|c|c|}
\hline Region & Cities name & Date interval & Data volume \\
\hline \multirow{24}{*}{ U.S. (24 cities) } & Atlanta & $01 / 01 / 1997-27 / 09 / 2016$ & 7210 \\
\hline & Baltimore & $01 / 01 / 1997-31 / 05 / 2016$ & 7091 \\
\hline & Boston & $01 / 01 / 1997-31 / 05 / 2016$ & 7091 \\
\hline & Chicago & 01/01/1997-27/09/2016 & 7210 \\
\hline & Cincinnati & 01/01/1997-27/09/2016 & 7210 \\
\hline & Colorado Springs & $01 / 05 / 2008-31 / 05 / 2016$ & 2953 \\
\hline & Dallas & 01/01/1997-27/09/2016 & 7210 \\
\hline & Des Moines & $01 / 01 / 1997-31 / 05 / 2016$ & 7091 \\
\hline & Detroit & $01 / 01 / 1997-31 / 05 / 2016$ & 7091 \\
\hline & Houston & $01 / 01 / 1997-31 / 05 / 2016$ & 7091 \\
\hline & Jacksonville & 01/05/2008-31/05/2016 & 2953 \\
\hline & Kansas City & 01/01/1997-31/05/2016 & 7091 \\
\hline & Las Vegas & $01 / 05 / 2008-27 / 09 / 2016$ & 3075 \\
\hline & Little Rock & $01 / 05 / 2008-31 / 05 / 2016$ & 2953 \\
\hline & Los Angeles & $01 / 05 / 2008-31 / 05 / 2016$ & 2953 \\
\hline & Minneapolis & $01 / 01 / 1997-27 / 09 / 2016$ & 7210 \\
\hline & New York & 01/01/1997-27/09/2016 & 7210 \\
\hline & Philadelphia & 01/01/1997-31/05/2016 & 7091 \\
\hline & Portland & $01 / 01 / 1997-31 / 05 / 2016$ & 7091 \\
\hline & Raleigh & $01 / 05 / 2008-31 / 05 / 2016$ & 2951 \\
\hline & Sacramento & 01/01/1997-27/09/2016 & 7210 \\
\hline & Salt Lake City & $01 / 01 / 1997-31 / 05 / 2016$ & 7091 \\
\hline & Tucson & $01 / 01 / 1997-31 / 05 / 2016$ & 7091 \\
\hline & Washington D.C. & $01 / 05 / 2008-31 / 05 / 2016$ & 2953 \\
\hline \multirow{11}{*}{ EUROPE (11 cities) } & Amsterdam & $14 / 09 / 2006-27 / 09 / 2016$ & 3670 \\
\hline & Barcelona & $16 / 11 / 2006-30 / 04 / 2016$ & 3457 \\
\hline & Berlin & $16 / 11 / 2006-30 / 04 / 2016$ & 3457 \\
\hline & Essen & $16 / 11 / 2006-30 / 04 / 2016$ & 3457 \\
\hline & London & 10/09/2006-27/09/2016 & 3670 \\
\hline & Madrid & $16 / 11 / 2006-30 / 04 / 2016$ & 3457 \\
\hline & Oslo & $01 / 05 / 2008-30 / 04 / 2016$ & 2917 \\
\hline & Paris & $16 / 11 / 2006-30 / 04 / 2016$ & 3457 \\
\hline & Prague & $01 / 01 / 2010-30 / 04 / 2016$ & 2310 \\
\hline & Rome & $16 / 11 / 2006-30 / 04 / 2016$ & 3457 \\
\hline & Stockholm & $16 / 11 / 2006-30 / 04 / 2016$ & 3457 \\
\hline \multirow{6}{*}{ CANADA (6 cities) } & Calgary & 20/06/2001-27/09/2016 & 5579 \\
\hline & Edmonton & $01 / 01 / 1997-27 / 09 / 2016$ & 7210 \\
\hline & Montreal & $01 / 01 / 1997-27 / 09 / 2016$ & 7210 \\
\hline & Toronto & $11 / 01 / 1997-20 / 05 / 2015$ & 6404 \\
\hline & Vancouver & 01/01/1997-27/09/2016 & 7210 \\
\hline & Winnipeg & 01/01/1997-27/09/2016 & 7210 \\
\hline \multirow{3}{*}{ AUSTRALIA ( 3 cities) } & Bankstown & 01/01/2009-09/27/2016 & 2827 \\
\hline & Melbourne & $01 / 01 / 2009-09 / 27 / 2016$ & 2827 \\
\hline & Sydney & 01/01/2009-09/27/2016 & 2827 \\
\hline \multirow{3}{*}{ JAPAN ( 3 cities) } & Hiroshima & $01 / 01 / 1997-27 / 09 / 2016$ & 7210 \\
\hline & Osaka & 01/01/1997-27/09/2016 & 7210 \\
\hline & Tokyo & $01 / 01 / 1997-27 / 09 / 2016$ & 7210 \\
\hline \multirow{14}{*}{ CHINA $(7$ cities $\times 2$ ) } & Beijing & $04 / 01 / 1998-31 / 12 / 2015$ & 6573 \\
\hline & Beijing2 & $04 / 01 / 1998-31 / 12 / 2015$ & 6573 \\
\hline & Harbin & 01/01/1997-27/09/2016 & 7210 \\
\hline & Harbin2 & $01 / 01 / 1997-27 / 09 / 2016$ & 7210 \\
\hline & Jinan & 01/01/1997-27/09/2016 & 7210 \\
\hline & Jinan2 & 01/01/1997-27/09/2016 & 7210 \\
\hline & Nanjing & 08/01/1998-31/12/2015 & 6569 \\
\hline & Nanjing2 & 01/01/1997-27/09/2016 & 7210 \\
\hline & Shanghai & $01 / 01 / 2003-31 / 12 / 2015$ & 4748 \\
\hline & Shanghai2 & $01 / 01 / 2003-31 / 12 / 2015$ & 4748 \\
\hline & Shenzhen & $01 / 01 / 1997-27 / 09 / 2016$ & 7210 \\
\hline & Shenzhen2 & 01/01/1997-27/09/2016 & 7210 \\
\hline & Sanya & 01/01/1997-27/09/2016 & 7210 \\
\hline & Sanya2 & 01/01/1997-27/09/2016 & 7210 \\
\hline
\end{tabular}



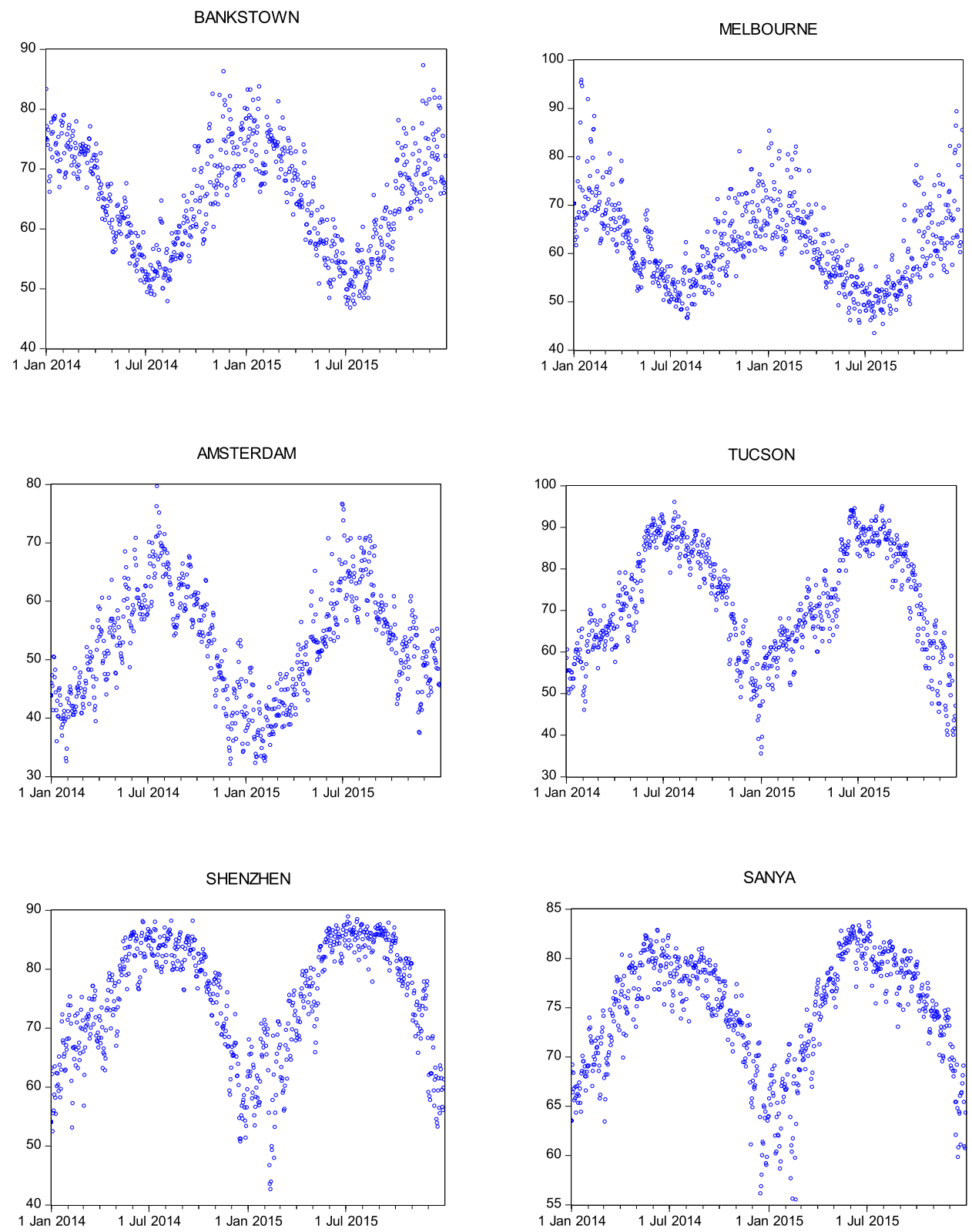

Fig. 1. $\mathrm{DAT}_{1}$ of six cities.

If Eq. (2) is as follows:

$$
\sigma_{t}^{2}=\alpha_{0}+\sum_{q=1}^{Q}\left(\lambda_{c, q} \cos \left(2 \pi q \frac{d(t)}{365}\right)+\lambda_{s, q} \sin \left(2 \pi q \frac{d(t)}{365}\right)\right)+\sum_{i=1}^{I} \alpha_{i} \varepsilon_{t-j}^{2}+\sum_{j=1}^{J} \beta_{j} \sigma_{t-j}^{2},
$$

it is AR-GARCH model by Campbell and Diebold [9], which cannot obviously catch the asymmetry of the volatility.

\subsection{Cluster analysis}

There are many clustering measures. Traditional clustering measures are mainly for static data, but temperature time series varies with time, which belongs to dynamic data. It is therefore very complex to cluster them. In recent years, many clustering measures for time series have come up, and can be divided into three types: clustering in the forms of raw data, extracted feature, or model parameters [41]. Clustering in the forms of raw data is to cluster directly high dimensional 
Table 4

Iteration history.

\begin{tabular}{llllll}
\hline Iteration & \multicolumn{5}{l}{ Change in cluster centers } \\
\cline { 2 - 6 } & 1 & 2 & 3 & 4 & 5 \\
\hline 1 & 3.6421 & 4.6007 & 4.5653 & 0.7958 & 3.3928 \\
2 & 0.0000 & 0.2229 & 0.2484 & 0.0000 & 0.0000 \\
3 & 0.0000 & 0.2115 & 0.2912 & 0.0000 & 0.0000 \\
4 & 0.0000 & 0.0000 & 0.0000 & 0.0000 & 0.0000 \\
\hline
\end{tabular}

time series. Thus, time and space complexity of the algorithm are increased. Clustering in the form of extracted feature and model parameters is to transform time series into static eigenvalues and model parameters, then use clustering measures for static data to indirectly cluster the time series. Especially clustering in the form of model parameters considers that similar time series should produce similar models, so the purpose of time series clustering can be achieved by comparing the similarity between the models.

In this paper, clustering in the form of model parameters is used to classify temperature time series data of different cities. There are two issues in this processing. One is to construct a proper model for temperature time series (see 3.2). Another is to use static clustering measure to classify the temperature data of different cities according to the model parameters. There are three classical static clustering measures: two-step clustering, system clustering and K-mean clustering. K-mean clustering is a widely classical clustering measure [42], which has the advantages of simple algorithm and fast speed; hence, we choose the K-mean clustering method in this study.

\section{Results}

\subsection{Parameters estimation of AR-EGARCH model}

According to the AR-EGARCH model, we considered repeated attempts, and set $R=1, L=3, P=Q=2, I=J=1$ so that $R^{2}, F$ statistic, AIC and SC criteria can reach optimum state. Q-statistics with twelve lags by Box-Pierce test show that standardized residuals squared have no significant autocorrelation, except for Atlanta, Baltimore and Chicago.

The data for the study showed that twenty-eight cities had no significant time trend under $5 \%$ significance level in the mean Equation (1). It implies that people have taken effective measures to alleviate the phenomenon in the last twenty years, although there is plenty of evidence to suggest that the rapid development of human society has brought about global warming in recent decades. Parameters of Fourier series in the mean Equation (1) and the variance Equation (2) are also significant under $5 \%$ significance level, indicating that there is a significant seasonality under $1 \%$ significance level in both temperature itself and its volatility.

From the sixty-one sets of data, the asymmetry coefficients $\gamma_{i}$ of only seven sets did not pass the $5 \%$ significance level. They involve these cities: Colorado, Las Vegas, Winnipeg, Edmonton, Barcelona, Madrid and Rome. In the remaining fiftyfour sets of data whose asymmetry coefficients $\gamma_{i}$ pass the significance test, there are six sets with negative $\gamma_{i}$. The cities involved are Tucson, Beijing, Shenzhen, and Sanya. In these four cities, the impact of temperature drop on the volatility is stronger than temperature rise. These results perhaps explain the phenomenon in Fig. 1; where the temperature volatility of Tucson, Shenzhen and Sanya in winter is higher than in summer. It means the temperature more easily falls significantly when the cold air strikes in winter, while a sharp drop in temperature will have a bigger impact on the volatility. Therefore, in the form of expression, temperature fluctuation in winter will be more obvious than in summer. For the cities with the positive $\gamma_{i}$, temperature fluctuation changing is opposite.

\subsection{K-mean clustering}

First, a classification of the forty-seven sets of data involving forty-seven cities, which have temperature derivatives in CME, was carried out. Before doing that, the initial classified number and the initial cluster centers were determined. After repeated attempts, the initial classified number was set to five. The initial cluster centers are determined by the software according to the characteristics of the input data. In this way, one can avoid the subjective factors. One can see the change history of the cluster center of each category in the iterative process from Table 4 . After four iterations, the algorithm converges. It means the initial cluster centers determined by the software are effective. Euclidean distances between five new cluster centers and their corresponding initial cluster centers are respectively 3.6421, 4.6007, 4.5653, 0.7958 , and 3.3928 after the first iteration. In the following three iterations, Euclidean distances between cluster centers gradually decrease, and are zero in the last iteration.

Table 5 shows the number of cases in each cluster. The first category consists of three members. The second category contains fifteen members; the third category contains twelve members; the fourth category contains three members; the fifth category contains fourteen members. The number of valid data is forty-seven; the number of missing data is zero.

Table 6 shows the cluster membership and the distance between the cluster members and their corresponding cluster centers. Compared with Table 7, it is found that the distance between each cluster member and the cluster center is less 
Table 5

Number of cases in each cluster.

\begin{tabular}{lrllll}
\hline Cluster & 1 & 2 & 3 & 4 & 5 \\
\hline Number of cases & 3 & 15 & 12 & 3 & 14 \\
Valid & 47 & & & & \\
Missing & 0 & & & & \\
\hline
\end{tabular}

Table 6

\begin{tabular}{lllllllll}
\multicolumn{2}{l}{ Cluster membership. } & \multicolumn{1}{l}{$l$} & & \\
Member & Cluster & Distance & Member & Cluster & Distance & Member & Cluster & Distance \\
\hline Altanta & 3 & 2.3366 & New York & 3 & 1.5498 & Prague & 5 & 6.6988 \\
Baltimore & 3 & 3.9906 & Philadelphia & 1 & 5.2834 & Rome & 5 & 1.3515 \\
Boston & 3 & 1.6898 & Portland & 2 & 2.9611 & Stockholm & 5 & 1.2614 \\
Chicago & 2 & 1.2065 & Raleigh & 3 & 2.6868 & Winnipeg & 2 & 1.3935 \\
Cincinnati & 2 & 1.2099 & Sacramento & 2 & 2.9315 & Vancouver & 2 & 1.4012 \\
Colorado & 3 & 2.7461 & Salt Lake City & 2 & 1.4910 & Toronto & 2 & 1.2439 \\
Dallas & 3 & 1.1740 & Tucson & 3 & 3.1191 & Montreal & 2 & 1.4622 \\
Des Moines & 2 & 1.3845 & Washington & 3 & 1.4349 & Edmonton & 2 & 3.3928 \\
Detroit & 2 & 1.0319 & Amsterdam & 5 & .7958 & Calgary & 1 & 1.1375 \\
Houston & 3 & 3.8297 & Barcelona & 5 & 1.7159 & Sydney & 4 & 1.6070 \\
Jacksonville & 3 & 4.1950 & Berlin & 5 & 1.2201 & Brisbane & 4 & 1.0992 \\
Kansas City & 2 & 1.6043 & Essen & 5 & 5.0033 & Melbourne & 4 & 1.7558 \\
Las Vegas & 2 & 2.7260 & London & 5 & 3.0209 & Osaka & 5 & 3.3535 \\
Little Rock & 3 & 1.1690 & Madrid & 5 & 2.2949 & Tokyo & 5 & 3.8746 \\
Los Angeles & 2 & 4.3761 & Oslo & 5 & 2.9412 & Hiroshima & 5 & 2.7112 \\
Minneapolis & 1 & 3.6421 & Paris & 5 & 4.2139 & & & \\
\hline
\end{tabular}

Table 7

Distance of final cluster centers.

\begin{tabular}{lrrrll}
\hline Cluster & \multicolumn{1}{l}{1} & \multicolumn{1}{l}{3} & \multicolumn{1}{l}{4} & \multicolumn{1}{l}{5} \\
\hline 1 & & 9.6454 & 11.5422 & 12.9051 & 11.6848 \\
2 & 9.6454 & & 5.3267 & 15.1088 & 11.4582 \\
3 & 11.5422 & 5.3267 & & 12.0605 & 16.5488 \\
4 & 12.9051 & 15.1088 & 12.0605 & & 22.3322 \\
5 & 11.6848 & 11.4582 & 16.5488 & 22.3322 & \\
\hline
\end{tabular}

than the distance between the cluster centers, which shows that the clustering result is effective. The United States is divided into three categories: two cities belong to the first category; ten cities belong to the second category; and twelve cities belong to the third category. Canada is divided into two categories. Except for Calgary, which belongs to the first category, the other five cities belong to the second category. Three cities in Australia belong to the fourth category. All the cities in Europe and Asia belong to the fifth category.

In Table 7, the minimum distance of cluster centers is 5.3267, which is between the second category and the third category. This is reasonable because the cities of the second category and the third category are neighbors in the United States. The maximum distance of cluster centers is 22.3322 , which is between the fourth category and the fifth category. The fourth category, Australia, is dominated by tropical deserts and grasslands climate. There are also subtropical monsoon humid climate and tropical rainforest climate in Australia. Therefore, there is a big difference with the fifth category, Europe and Japan, in their climate such that the distance of the cluster center is very big.

Finally, the validity of the whole model is further verified by ANOVA variance analysis. In Table 8, with the exception of $\rho_{t-3}$ which did not pass the significance test and $\alpha_{1}$ which passed the $10 \%$ significance test, the other parameters passed the $5 \%$ significance test.

Based on the classification of forty-seven cities in CME, fourteen sets of data from the other seven cities in China were added into the classification. The software was still used to determine the initial cluster centers. In determining the initial classified number, we started with five, and in turn, try six, seven ... twelve to find the best-classified number. It turns out that the sixty-one sets of data can be divided into eleven categories, and still maintain the original classified relationship for forty-seven cities. As a result, the new fourteen sets of data belong to either the original categories of forty-seven cities or a new category.

Table 9 shows the iteration history. The algorithm converges after three iterations. After the first iteration, Euclidean distances between the new eleven cluster centers and the initial cluster centers are respectively 0.5067, 3.4490, 0.7958, $2.4459,5.0002,2.2893,0.3103,1.8531,4.4226,3.7763$, and 4.5412. In the following two iterations, Euclidean distances rapidly reduce to zero, and cluster iteration is over.

One can see the number of cases in each cluster from Table 10. The first category, the second category, the fourth category, the sixth category, the seventh category and the tenth category include two cluster members respectively. The third category includes three cluster members. The fifth category includes four cluster members. The eighth category 
Table 8

ANOVA variance analysis.

\begin{tabular}{|c|c|c|c|c|c|c|}
\hline \multirow[t]{2}{*}{ Variable } & \multicolumn{2}{|l|}{ Cluster } & \multicolumn{2}{|l|}{ Error } & \multirow[t]{2}{*}{$\mathrm{F}$} & \multirow[t]{2}{*}{ Sig. } \\
\hline & Mean square & df & Mean square & df & & \\
\hline$\phi_{0}{ }^{* * *}$ & 543.3433 & 4 & 3.9357 & 42 & 138.0565 & 0.0000 \\
\hline$\phi_{1}^{* *}$ & 0.0000 & 4 & 0.0000 & 42 & 2.3534 & 0.0493 \\
\hline$\delta_{c, 1}{ }^{* * *}$ & 121.7976 & 4 & 1.8456 & 42 & 65.9933 & 0.0000 \\
\hline$\delta_{s, 1}{ }^{* * *}$ & 13.2299 & 4 & 1.0849 & 42 & 12.1946 & 0.0000 \\
\hline$\delta_{c, 2}^{* *}$ & 0.0990 & 4 & 0.0426 & 42 & 2.3227 & 0.0323 \\
\hline$\delta_{s, 2} * * *$ & 14.6085 & 4 & 0.8885 & 42 & 16.4409 & 0.0000 \\
\hline$\rho_{t-1}{ }^{* * *}$ & 3.3221 & 4 & 0.1738 & 42 & 19.1194 & 0.0000 \\
\hline$\rho_{t-2}{ }^{* * *}$ & 0.0607 & 4 & 0.0043 & 42 & 13.9783 & 0.0000 \\
\hline$\rho_{t-3}$ & 0.0037 & 4 & 0.0021 & 42 & 1.8116 & 0.1446 \\
\hline$\alpha_{0}^{* *}$ & 1.9862 & 4 & 0.5797 & 42 & 3.4261 & 0.0164 \\
\hline$\alpha_{1}^{*}$ & 0.0130 & 4 & 0.0052 & 42 & 2.4886 & 0.0577 \\
\hline$\gamma_{1}^{* * *}$ & 0.0292 & 4 & 0.0053 & 42 & 5.5321 & 0.0011 \\
\hline$\beta_{1}^{* *}$ & 0.0482 & 4 & 0.0716 & 42 & 0.6734 & 0.0142 \\
\hline$\lambda_{c, 1}{ }^{* * *}$ & 0.1123 & 4 & 0.0172 & 42 & 6.5355 & 0.0003 \\
\hline$\lambda_{s, 1}{ }^{* * *}$ & 0.0416 & 4 & 0.0080 & 42 & 5.2247 & 0.0017 \\
\hline$\lambda_{c, 2}{ }^{* *}$ & 0.0099 & 4 & 0.0030 & 42 & 3.2609 & 0.0204 \\
\hline$\lambda_{s, 2}{ }^{* * *}$ & 0.0085 & 4 & 0.0013 & 42 & 6.5053 & 0.0004 \\
\hline
\end{tabular}

Note:

$\mathrm{F}=$ Cluster mean square/Error mean square.

* $10 \%$ significance level.

**5\% significance level.

*** $1 \%$ significance level.

Table 9

Iteration history.

\begin{tabular}{|c|c|c|c|c|c|c|c|c|c|c|c|}
\hline \multirow[t]{2}{*}{ Iteration } & \multicolumn{11}{|c|}{ Change in cluster centers } \\
\hline & 1 & 2 & 3 & 4 & 5 & 6 & 7 & 8 & 9 & 10 & 11 \\
\hline 1 & 0.5067 & 3.4490 & 0.7958 & 2.4459 & 5.0002 & 2.2893 & 0.3103 & 1.8531 & 4.4226 & 3.7763 & 4.5412 \\
\hline 2 & 0.0000 & 0.0000 & 0.0000 & 0.0000 & 1.9206 & 0.0000 & 0.0000 & 0.0000 & 0.0000 & 0.0000 & 0.7015 \\
\hline 3 & 0.0000 & 0.0000 & 0.0000 & 0.0000 & 0.0000 & 0.0000 & 0.0000 & 0.0000 & 0.0000 & 0.0000 & 0.0000 \\
\hline
\end{tabular}

Table 10

Number of cases in each cluster.

\begin{tabular}{|c|c|c|c|c|c|c|c|c|c|c|c|}
\hline Cluster & 1 & 2 & 3 & 4 & 5 & 6 & 7 & 8 & 9 & 10 & 11 \\
\hline Number of cases & 2 & 2 & 3 & 2 & 4 & 2 & 2 & 16 & 12 & 2 & 14 \\
\hline Valid & 61 & & & & & & & & & & \\
\hline Missing & 0 & & & & & & & & & & \\
\hline
\end{tabular}

includes sixteen cluster members. In addition, the ninth category includes twelve cluster members. The eleventh category includes fourteen cluster members. The number of valid data is sixty-one; the number of missing data is 0 .

Table 11 shows the category each city belongs to and the distance between cluster members and their corresponding cluster centers. Compared with Table 6, there are eleven categories in Table 11, and the classified result of the first fortyseven cities is nearly the same, except for Las Vegas, Los Angeles, and Portland. The result suggests the latter clustering is based on the previous clustering.

Because of the new numerical order, Table 12 shows the change of the first five numerical orders in Tables 6 and 11 . The fifth category in Table 11 corresponds to the first category in Table 6 . The ninth category in Table 11 corresponds to the second category in Table 6, and so on.

The United States is still divided into three categories: Three cities belong to the fifth category; seven cities belong to the ninth category; and fourteen cities belong to the eleventh category. In Canada, except for Calgary, which belongs to the fifth category, the other five cities belong to the ninth category. Three cities in Australia belong to the third category. All cities in Europe and Japan belong to the eighth category.

In the other fourteen sets of the Chinese data, only two sets of data in Nanjing, which include Nanjing $\left(\mathrm{DAT}_{1}\right)$ and Nanjing2 $\left(\mathrm{DAT}_{2}\right)$, belong to the eighth category, which is the same category as Europe and Japan, while the rest of six cities belong to the different categories with the forty-seven cities in CME. Beijing and Beijing2 belong to the second category. Harbin and Harbin2 belong to the seventh category; Jinan and Jinan2 belong to the first category; Shanghai and Shanghai2 belong to the sixth category; Shenzhen and Shenzhen2 belong to the fourth category; and Sanya and Sanya2 belong to the tenth category. There are HDD and CAT in Europe and CAT* in Japan, so the three temperature derivatives could be suitable for Nanjing, but not the other Chinese cities. CDD cannot be used directly in the seven Chinese cities. 
Table 11

Cluster membership.

\begin{tabular}{|c|c|c|c|c|c|c|c|c|}
\hline Member & Cluster & Distance & Member & Cluster & Distance & Member & Cluster & Distance \\
\hline Altanta & $11(3)$ & 1.9647 & Sacramento & $9(2)$ & 3.5920 & Calgary & $5(1)$ & 1.2415 \\
\hline Baltimore & $11(3)$ & 3.8875 & Salt Lake City & $9(2)$ & 1.3948 & Sydney & $3(4)$ & 1.4945 \\
\hline Boston & $11(3)$ & 1.8200 & Tucson & $11(3)$ & 2.7446 & Brisbane & $3(4)$ & 1.2092 \\
\hline Chicago & $9(2)$ & 1.0070 & Washington & $11(3)$ & 1.8311 & Melbourne & $3(4)$ & 1.8531 \\
\hline Cincinnati & $9(2)$ & 1.5564 & Amsterdam & $8(5)$ & 0.7958 & Osaka & $8(5)$ & 3.2368 \\
\hline Colorado & $11(3)$ & 2.4792 & Barcelona & $8(5)$ & 1.7159 & Tokyo & $8(5)$ & 3.7510 \\
\hline Dallas & $11(3)$ & 1.0198 & Berlin & $8(5)$ & 1.2201 & Hiroshima & $8(5)$ & 2.6129 \\
\hline Des Moines & $9(2)$ & 0.9572 & Essen & $8(5)$ & 4.4226 & Nanjing & 8 & 2.1141 \\
\hline Detroit & $9(2)$ & 0.9119 & London & $8(5)$ & 3.4315 & Nanjing2 & 8 & 2.0218 \\
\hline Houston & $11(3)$ & 4.2014 & Madrid & $8(5)$ & 2.1196 & Beijing & 2 & 3.4490 \\
\hline Jacksonville & $11(3)$ & 4.5653 & Oslo & $8(5)$ & 2.5065 & Beijing2 & 2 & 3.4490 \\
\hline Kansas City & $9(2)$ & 1.8228 & Paris & $8(5)$ & 3.7259 & Harbin & 7 & 0.3103 \\
\hline Las Vegas & $11(2)$ & 3.2296 & Prague & $8(5)$ & 6.3847 & Harbin2 & 7 & 0.3103 \\
\hline Little Rock & $11(3)$ & 0.7519 & Rome & $8(5)$ & 1.5097 & Jinan & 1 & 0.5067 \\
\hline Los Angeles & $5(2)$ & 4.9345 & Stockholm & $8(5)$ & 1.3505 & Jinan2 & 1 & 0.5067 \\
\hline Minneapolis & $5(1)$ & 4.4954 & Winnipeg & $9(2)$ & 1.4640 & Shanghai & 6 & 2.2893 \\
\hline New York & $11(3)$ & 1.3958 & Vancouver & $9(2)$ & 1.5387 & Shanghai2 & 6 & 2.2893 \\
\hline Philadelphia & $5(1)$ & 5.7617 & Toronto & $9(2)$ & 1.4162 & Shenzhen & 4 & 2.4459 \\
\hline Portland & $11(2)$ & 3.2821 & Montreal & $9(2)$ & 1.4884 & Shenzhen2 & 4 & 2.4459 \\
\hline \multirow[t]{2}{*}{ Raleigh } & $11(3)$ & 3.1766 & Edmonton & $9(2)$ & 3.5541 & Sanya & 10 & 3.7763 \\
\hline & & & & & & Sanya2 & 10 & 3.7763 \\
\hline
\end{tabular}

Note: the numbers in the brackets are the numerical orders of the previous clustering.

Table 12

Change of Tables 6 and 11 cluster.

\begin{tabular}{llllll}
\hline Table 6 & 1 & 2 & 3 & 4 & 5 \\
Table 11 & 5 & 9 & 11 & 3 & 8 \\
\hline
\end{tabular}

Table 13

ANOVA variance analysis.

\begin{tabular}{|c|c|c|c|c|c|c|}
\hline \multirow[t]{2}{*}{ Variable } & \multicolumn{2}{|l|}{ Cluster } & \multicolumn{2}{|l|}{ Error } & \multirow[t]{2}{*}{$\mathrm{F}$} & \multirow[t]{2}{*}{ Sig. } \\
\hline & Mean square & df & Mean square & df & & \\
\hline$\phi_{0}^{* * *}$ & 1374.7126 & 10 & 4.3721 & 50 & 314.4297 & 0.0000 \\
\hline$\phi_{1}^{* *}$ & 0.0000 & 10 & 0.0000 & 50 & 37.0070 & 0.0000 \\
\hline$\delta_{c, 1}{ }^{* * * *}$ & 1110.4773 & 10 & 1.5492 & 50 & 716.8029 & 0.0000 \\
\hline$\delta_{s, 1} * * *$ & 78.4971 & 10 & 0.9691 & 50 & 81.0026 & 0.0000 \\
\hline$\delta_{c, 2} * * *$ & 10.8445 & 10 & 0.0402 & 50 & 269.7731 & 0.0000 \\
\hline$\delta_{s, 2}{ }^{* * *}$ & 6.0747 & 10 & 1.0716 & 50 & 5.6691 & 0.0000 \\
\hline$\rho_{t-1}{ }^{* * *}$ & 0.9668 & 10 & 0.2263 & 50 & 4.2715 & 0.0003 \\
\hline$\rho_{t-2}{ }^{* * *}$ & 0.0266 & 10 & 0.0050 & 50 & 5.3404 & 0.0000 \\
\hline$\rho_{t-3}{ }^{*}$ & 0.0028 & 10 & 0.0016 & 50 & 1.7555 & 0.0941 \\
\hline$\alpha_{0}^{* * *}$ & 6.5687 & 10 & 0.9563 & 50 & 6.8689 & 0.0000 \\
\hline$\alpha_{1}^{* *}$ & 0.0107 & 10 & 0.0049 & 50 & 2.1568 & 0.0367 \\
\hline$\gamma_{1}^{* * *}$ & 0.0338 & 10 & 0.0047 & 50 & 7.1565 & 0.0000 \\
\hline$\beta_{1}^{* *}$ & 0.1587 & 10 & 0.0734 & 50 & 2.1634 & 0.0361 \\
\hline$\lambda_{c, 1}{ }^{* * *}$ & 0.0754 & 10 & 0.0167 & 50 & 4.5216 & 0.0001 \\
\hline$\lambda_{s, 1} * * *$ & 0.0478 & 10 & 0.0074 & 50 & 6.4284 & 0.0000 \\
\hline$\lambda_{c, 2}{ }^{* *}$ & 0.0059 & 10 & 0.0026 & 50 & 2.3026 & 0.0259 \\
\hline$\lambda_{s, 2} * * *$ & 0.0110 & 10 & 0.0014 & 50 & 7.7720 & 0.0000 \\
\hline
\end{tabular}

Note:

$\mathrm{F}=$ Cluster mean square/Error mean square.

${ }^{*} 10 \%$ significance level.

** $5 \%$ significance level.

*** $1 \%$ significance level.

Finally, the validity of the whole model is further verified by ANOVA variance analysis (Table 13) where $\alpha_{1}$ passed the $10 \%$ significance test, and the other parameters passed the $5 \%$ significance test.

\section{Conclusion and recommendations}

We used cluster analysis on temperature data to classify forty-seven cities in CME and seven cities in China. For temperature time series, cluster analysis in the form of model parameters was better. Thus, the AR-EGARCH model was applied to fit temperature data, and then cluster analysis. AR-EGARCH model is an extension of AR-GARCH model because 
it can factor in the asymmetry of the temperature fluctuation. The results show that asymmetry parameters $\gamma_{i}$ of just seven sets in the sixty-one sets of temperature data are not significant, and the fitting effect is good. $\gamma_{i}$ is positive in some cities and negative in other cities. It suggests that in some cities the heat wave had greater impact on temperature changes, while in other cities the strong cold air had greater impact.

Based on the results of the AR-EGARCH model, K-mean clustering measure was used to classify the temperature data of cities. A 2-step approach was used: first of all, temperature data of forty-seven cities with temperature derivatives in the CME are classified to get basic classified criteria. Secondly, the temperature data of the seven Chinese cities were added to the classified program based on the previous classified criteria. The results show that Harbin, Beijing, Jinan, Shanghai, Shenzhen and Sanya cannot directly use all the existing temperature derivatives in the CME, but Nanjing can directly use HDD, CAT and CAT*. We concluded that temperature-index derivatives from the CME are not necessarily suitable for the selected cities in China based on our assumptions and the model used. That notwithstanding, the relevance of weather derivative market to the economy of China cannot be underestimated.

The following recommendations are therefore put forward for the establishment of China's weather derivatives market: (1) The introduction of weather derivatives into China is feasible

Weather derivatives market can attract social capital to participate in the dispersion of meteorological risk for enterprises closely related to climate. It is the most convenient way for China to directly introduce a mature weather derivative into its economy. However, weather derivatives have a strong regional characteristic, and products suitable for foreign cities are not surely suitable for China. In this paper, we proposed a method for the determination of the suitability of introducing weather derivatives into China. This research is a good proof. On the other hand, since the reform and opening up, the Chinese economy has developed rapidly, and financial markets continue to improve, and the Chinese market seems well prepared for the introduction of weather derivatives.

(2) Designing weather derivatives suitable for China's climate

Existing weather derivatives are not surely suitable for China, which requires designing new products to adapt to Chinese climate changes. The development of weather derivatives would not only enrich the types of investment for investors, but also help to promote Chinese financial engineering innovation, and train financial engineers. At the same time, it would also make it conducive for the Chinese financial industry to participate in the competition of the international financial market.

(3) Policy makers should introduce relevant policies and regulations

The establishment of a perfect market of weather derivatives is supported by a highly developed and multi-level capital market. At present, the scale of Chinese capital market is still not large enough, and the insurance market and the futures and options market are not developed completely. Some weather derivatives are designed on the basis of agricultural insurance and options. Therefore, the Chinese government should introduce relevant policies and regulations to promote the development and improvement of the insurance market, the futures and options market.

We conclude by stating that in this paper, we made a key assumption that when temperatures in two cities have the same dynamic evolution, the two cities can use the same types of temperature derivatives. From the perspective of risk management, when the risk source is homogeneous and its dynamic evolution is the same, perhaps it is possible to use the same types of risk management tools for hedging. This may seem more applicable to temperature risk because temperature is an objective phenomenon and does not change with human behavior and ideas. The question as to whether the temperature derivatives used in this study will be applicable to China still needs further probing through other modeling techniques and test. This notwithstanding, our study provides contributes need to solve the problem that lack of weather derivatives in China.

\section{Acknowledgments}

We are grateful to the editors and anonymous reviewers for their helpful comments, which greatly improved the earlier draft. This work was supported by National Natural Science Foundation of China [grant numbers 71701104]; Humanities and Social Sciences Foundation of Ministry of Education of China [grant numbers 17YJC790102]; Top-notch Academic Programs Project of Jiangsu Higher Education Institutions, China [grant numbers PPZY2015A072]

\section{References}

[1] M. Caporin, J. Preś, H. Torro, Model based Monte Carlo pricing of energy and temperature Quanto options, Energy Econ. 34 (2012) $1700-1712$.

[2] M. Buchholz, O. Musshoff, The role of weather derivatives and portfolio effects in agricultural water management, Agric. Water Manag. 146 (2014) 34-44.

[3] Z. Lu, E. Manuela, Spatially-aggregated temperature derivatives: Agricultural risk management in China, Int. J. Financ. Stud. 4 (2016) 1-17.

[4] A.K. Alexandridis, A.D. Zapranis, Weather Derivatives, Springer, New York, 2013, pp. 1-20.

[5] Z. Lu, E. Manuela, Model comparison for temperature-based weather derivatives in mainland China, Emerg. Mark. Financ. Trade 50 (2014) $68-86$.

[6] Z. Wang, P. Li, L. Li, C. Huang, M. Liu, Modeling and forecasting average temperature for weather derivative pricing, Adv. Meteorol. 2015 (2015) $1-8$.

[7] J.D. Woodard, P. Garcia, Basis risk and weather hedging effectiveness, Agric. Financ. Rev. 68 (2008) 99-117.

[8] S. Hong, S.Y. Sohn, Peer group analysis for introducing weather derivatives for a city, Expert Syst. Appl. 40 (2013) $5680-5687$.

[9] S.D. Campbell, F.X. Diebold, Weather forecasting for weather derivatives, J. Amer. Statist. Assoc. 100 (2005) 6-16. 
[10] H. Guo, H. Kassa, M.F. Ferguson, On the relation between EGARCH idiosyncratic volatility and expected stock returns, J. Financ. Quant. Anal. 49 (2014) 271-296.

[11] G. Mahsa, S. Rasoul, Improving value-at-risk estimation from the normal EGARCH model, Contemp. Econ. 11 (2017) 91-106.

[12] P.H. Franses, J. Neele, D.V. Dijk, Modeling asymmetric volatility in weekly dutch temperature data, Environ. Model. Softw. 16 (2001) $131-137$.

[13] A. Groll, B. López-Cabrera, T. Meyer-Brandis, A consistent two-factor model for pricing temperature derivatives, Energy Econ. 55 (2016) $112-126$.

[14] D.C. Brody, J. Syroka, M. Zervos, Dynamical pricing of weather derivatives, Quant. Finance 2 (2002) 189-198.

[15] G. Ahmet, Pricing temperature-based weather derivatives in China, J. Risk Financ. Inc. Balance Sheet 13 (2012) 32-44.

[16] A.E. Clements, A.S. Hurn, K.A. Lindsay, A closed-form approximation for pricing temperature-based weather derivatives, Appl. Math. 4 (2013) $1347-1360$.

[17] S. Jewson, A. Brix, Weather Derivative Valuation: The Meteorological, Statistical, Financial and Mathematical Foundations, Cambridge University Press, 2005.

[18] M. Davis, Pricing weather derivatives by marginal value, Quant. Finance 1 (2001) 305-308.

[19] G. Dorfleitner, M. Wimmer, The pricing of temperature futures at the Chicago Mercantile Exchange, J. Bank. Financ. 34 (2010) $1360-1370$.

[20] A. Brix, S. Jewson, C. Ziehmann, Weather derivative modelling and valuation: A statistical perspective, in: R.S. Dischel (Ed.), Climate Risk and the Weather Market, Risk books, England, 2002, pp. 127-150.

[21] A. Ahčan, Statistical analysis of model risk concerning temperature residuals and its impact on pricing weather derivatives, Insurance Math. Econom. 50 (2012) 131-138.

[22] A.K. Alexandridis, A.D. Zapranis, Weather Derivatives, Springer, New York, 2013, pp. 55-85.

[23] P. Alaton, B. Djehiche, D. Stillberger, On modelling and pricing weather derivatives, Appl. Math. Finance 9 (2002) 1-20.

[24] F.E. Benth, On arbitrage-free pricing of weather derivatives based on fractional brownian motion, Appl. Math. Finance 10 (2003) $303-324$.

[25] F.E. Benth, J. Šaltyte Benth, Stochastic modelling of temperature variations with a view towards weather derivatives, Appl. Math. Finance 12 (2005) 53-85.

[26] F.E. Benth, J. Šaltyte Benth, The volatility of temperature and pricing of weather derivatives, Quant. Finance 7 (2007) $553-561$.

[27] F.E. Benth, J. Šaltytė Benth, S. Koekebakker, Putting a price on temperature, Scand. J. Stat. 34 (2007) 746-767.

[28] F.E. Benth, J. Šaltyte Benth, S. Koekebakker, Stochastic Modelling of Electricity and Related Markets, World Scientific, 2008.

[29] A. Zapranis, A. Alexandridis, Modelling temperature time dependent speed of mean reversion in the context of weather derivative pricing, Appl. Math. Finance 15 (2008) 355-386.

[30] A. Zapranis, A. Alexandridis, Modeling and forecasting CAT and HDD indices for weather derivative pricing, in: D. Palmer-Brown, C. Draganova, E. Pimenidis, H. Mouratidis (Eds.), Engineering Applications of Neural Networks. EANN 2009. Communications in Computer and Information Science, Vol. 43, Springer, Berlin, Heidelberg, 2009, pp. 210-222.

[31] A. Zapranis, A. Alexandridis, Weather derivatives pricing: modelling the seasonal residuals variance of an Ornstein-Uhlenbeck temperature process with neural networks, Neurocomputing 73 (2009) 37-48.

[32] M. Moreno, Riding the Temp, Weather Derivatives, FOW Special Supplement, 2000.

[33] R.S.J. Tol, Autoregressive conditional heteroscedasticity in daily temperature measurements, Environmetrics 7 (1996) 67-75.

[34] J.W. Taylor, R. Buizza, A comparison of temperature density forecasts from GARCH and atmospheric models, J. Forecast. 23 (2004) $337-355$.

[35] J.W. Taylor, R. Buizza, Density forecasting for weather derivative pricing, Int. J. Forecast. 22 (2006) 29-42.

[36] M. Cao, J. Wei, Weather derivatives valuation and market price of weather risk, J. Futures Mark. 24 (2004) 1065-1089.

[37] F. Bellini, The Weather Derivatives Market: Modelling and Pricing Temperature, University of Lugano, Lugano, Switzerland, 2005, Submitted for the degree of Ph.D. in Economics at Faculty of Economics.

[38] M. Caporin, J. Prés, Forecasting temperature indices Density with time-varying long-memory models, J. Forecast. 32 (2013) 339-352.

[39] J. Svec, M. Stevenson, Modelling and forecasting temperature based weather derivatives, Glob. Financ. J. 18 (2007) 185-204.

[40] H. Cui, J. Zhang, J. He, The air temperature forecasting model based on AR-EGARCH, Statist. Inform. Forum 28 (2013) 36-41, (in Chinese)

[41] T.W. Liao, Clustering of time series data-a survey, Pattern Recognit. 38 (2005) 1857-1874.

[42] T.V. Le, N. Kabachi, M. Lamure, A clustering method associated pretopological concepts and k-means algorithm, in: C.H. Skiadas (Ed.), Recent Advances in Stochastic Modeling and Data Analysis, Chania, Greece, 2007, pp. 529-536. 